\title{
Nasal Cavity and Paranasal Sinuses Cancer cN2b TNM Finding v8
}

National Cancer Institute

\section{Source}

National Cancer Institute. Nasal Cavity and Paranasal Sinuses Cancer cN2b TNM Finding v8. NCI Thesaurus. Code C133054.

Nasal cavity and paranasal sinuses cancer with metastases in multiple ipsilateral lymph nodes, none larger than $6 \mathrm{~cm}$ in greatest dimension and ENE(-). (from AJCC 8th Ed.) 